\title{
Exercícios etnográficos como atividades em espaço público: Terapia Ocupacional Social no fazer da arte, da cultura e da política
}

\author{
Debora Galvani $^{\mathrm{a}, \mathrm{b}}$, Denise Dias Barros ${ }^{\mathrm{b}, \mathrm{d}}$, Marina Di Napoli Pastore ${ }^{\mathrm{b}, \mathrm{c}}$, Miki Takao Sato $^{\mathrm{b}, \mathrm{c}}$ \\ aDepartamento de Saúde, Educação e Sociedade, Universidade Federal de São Paulo - UNIFESP, Santos, SP, Brasil. \\ búcleo Amanar, Casa das Áfricas, São Paulo, SP, Brasil. \\ 'Universidade Federal de São Carlos - UFSCar, São Carlos, SP, Brasil. \\ dUniversidade de São Paulo - USP, São Paulo, SP, Brasil.
}

\begin{abstract}
Resumo: Discutem-se os exercícios etnográficos - realizados em propostas do Projeto Metuia/USP, entre 2007 e 2013 - como atividade capaz de potencializar o reconhecimento do saber composto, plural e, por vezes, contraditório, mas produzido criativamente no fazer intelectual e social, na interação entre estudantes, terapeutas ocupacionais, pesquisadores e pessoas em situação de rua. Parte-se da necessidade de se desenvolver a compreensão sobre as atividades significativas de artistas que trabalham nos espaços públicos da cidade de São Paulo, pois persiste uma pluralidade de significados que a rua adquire em meio a disputas de interesses e tensões culturais, mas, também, de interconexões e criatividade. A vida itinerante e as características dos espaços de sociabilidade, aliadas às reflexões da antropologia urbana e da pesquisa etnográfica, favoreceram o ensino teórico-prático em ações territoriais dialógicas da terapia ocupacional social. Este artigo é resultado de reflexões construídas a partir da pesquisa Circuitos e práticas religiosas nas trajetórias de vida de adultos em situação de rua na cidade de São Paulo, associado ao projeto de extensão universitária vinculada ao Projeto Metuia/Terapia Ocupacional/USP, denominado Ponto de encontro e cultura: redes sociais, cultura e terapia ocupacional social. Conclui-se, por um lado, que há necessidade da reflexão renovada sobre o lugar do terapeuta ocupacional, considerando as assimetrias das relações na construção do conhecimento. Por outro lado, indica-se que as atividades produzidas em relações dialógicas adquirem sentidos partilhados apenas quando desenhadas na experiência da diferença, em propostas coerentes com sua plasticidade própria e no bojo de contextos sociais e culturais específicos.
\end{abstract}

Palavras-chave: População em Situação de Rua, Artistas de Rua, Terapia Ocupacional Social, Ensino de Graduação, Artes, Etnografia.

\section{Ethnographic exercises as activities in public space: Social Occupational Therapy in art, culture and politics}

\begin{abstract}
Ethnographic exercises are discussed - as proposed by the Metuia Project/ USP between 2007 and 2013 - as an activity able to enhance the recognition of the compound, plural and sometimes contradictory knowledge, but produced creatively in the intellectual and social do, in the interaction among students, occupational therapists, researchers and homeless people. It starts from the need to develop an understanding of the significant activities of artists working in the public spaces in São Paulo, as it persists as a plurality of meanings that the street acquires amid disputes of interests and cultural tensions, but also interconnections and creativity. The itinerant life and social areas' characteristics, combined with reflections of urban anthropology and ethnographic research favored the theoretical and practical teaching in dialogic territorial shares of social occupational therapy. This article is the result
\end{abstract}

Autor para correspondência: Debora Galvani, Departamento de Saúde, Educação e Sociedade, Universidade Federal de São Paulo, Rua Silva Jardim, 136, Térreo, Vila Mathias, CEP 11015-020, Santos, SP, Brasil, e-mail: degalvani@gmail.com

Recebido em Maio 22, 2016; $1^{\text {a }}$ Revisão em Set. 22, 2016; $2^{\text {a }}$ Revisão em Out. 13, 2016; Aceito em Out. $24,2016$. 
of reflections built from the research Circuits and religious practices in life trajectories of adult homeless people in city of São Paulo, associated with university extension project linked to Metuia Project/USP, called Point meeting and culture: social networks, culture and social occupational therapy. In conclusion, on the one hand, there is need for renewed reflection about the occupational therapist's place, considering the asymmetries of the relations in the construction of knowledge. On the other hand, it indicates that the produced activities, necessarily, in dialogical relations, only share meanings when inserted into the experience of the difference in consistent proposals with its own plasticity and in the middle of specific social and cultural contexts.

Keywords: Homeless, Street Artists, Social Occupational Therapy, Undergraduate Education, Arts, Ethnography.

"O que se buscava era um plural sem igualdade, sem in-diferença” (BARTHES, 2003, p. 79).

\section{Introdução}

O ensino de graduação conhece múltiplas modalidades e situações, que se somam às metodologias e reflexôes em sala de aula. Aliando teoria e prática, desenvolvemos processos educativos em terapia ocupacional social, conduzidos por meio de práticas coletivas de pesquisas no interior de projetos de extensão universitária. Neste contexto, o ensino é concebido como ação e reflexão realizadas na experiência e na experimentação dialogada entre docentes, terapeutas ocupacionais, população - neste caso, pessoas em situação de rua na cidade de São Paulo - e estudantes.

Este artigo é resultado de estudos sobre artistas vivendo e/ou trabalhando nos espaços públicos do centro da cidade de São Paulo. Trabalhamos com uma metodologia alicerçada em processos e em relaçóes dialógicas, numa perspectiva freiriana (FREIRE, 2011), conduzidos por estudantes e educadores a partir de iniciativas que denominamos "exercícios etnográficos”, entre 2007 e 2013. Por meio destes, buscou-se repensar tanto os lugares da ação do terapeuta ocupacional como as narrativas sobre a cidade, consideradas na perspectiva de diferentes pessoas que conheceram a experiência da situação de rua. Estes circuitos (MAGNANI, 2002) de artistas, que atuam nas praças e em outros espaços públicos, exigiram, em um primeiro momento, uma ruptura de fronteiras - simbólicas, sociais, culturais e de classe - erguidas cotidianamente entre os diferentes universos que se entrecruzam sem se reconheceram nos espaços urbanos. Neste sentido, os exercícios etnográficos constituíram-se como parte das estratégias criadas para desconstrução do olhar preso a estereotipias, como estratégia para se estabelecerem passagens, trocas e diálogos, a fim de criar possibilidades de construção de conhecimentos compartilhados. Foram importantes, para a análise, as reflexóes realizadas no âmbito do Ponto de encontro e cultura: redes sociais, cultura e terapia ocupacional social (2007 e 2013) - iniciativa de ensino, pesquisa e extensão universitária vinculada ao Projeto Metuia-USP ${ }^{1}$-, e na pesquisa Circuitose práticas religiosas nas trajetórias de vida de adultos em situação de rua na cidade de São Paulo, conduzida por Galvani (2015), uma das autoras deste artigo.

\section{Exercícios Etnográficos e Ética Dialógica: A Rua dos Artistas e de Diversidades Entrelaçadas}

Retomamos as reflexôes de três narrativas desenhadas a partir de exercícios etnográficos desenvolvidos no contexto do Ponto de Encontro e Cultura PEC/Projeto Metuia-USP (PEC), realizadas coletivamente por estudantes, membros do PEC e educadores (docentes e supervisores de estágio). O PEC, como ficou conhecido, caracterizou-se como espaço de articulação e encontros entre diversos saberes e linguagens de expressóes culturais e de classe, construído conjuntamente por profissionais do Projeto Metuia/USP, lideranças dos movimentos de defesa de direitos da população em situação de rua, artistas, estudantes de Terapia Ocupacional da USP, vendedores e voluntários da Organização Civil de Ação Social (OCAS), além de outras pessoas que se interessaram em participar. O espaço - como ambiente de criação e expressão cultural, artística, política e de saberes - era sediado em uma casa no bairro do Brás, cedida pela Associação Rede Rua, que, à época, sediava, também, o Movimento dos Trabalhadores Rurais Sem Terra e a OCAS (BARROS et al., 2013; BARROS; GALVANI, 2016). Foram inúmeras iniciativas desenvolvidas entre 2007 e 2012, dentre as quais, os exercícios etnográficos com foco no circuito dos músicos de rua, cujo espaço de intervenção artística se dava no centro da cidade de São Paulo.

"Por que, em várias cidades do mundo, artistas de rua são reconhecidos como atração turística, 
inclusive, e aqui, na cidade de Sáo Paulo, são perseguidos?", "Será que a populaçẫo da cidade tem noção da qualidade dos artistas que estão na rua?", "Por que quem usa a rua para divulgar sua arte é confundido com bandido?" Foram essas perguntas, que tiveram como contexto um momento histórico de maior regulação sobre o espaço público, sobretudo no centro da cidade de São Paulo, que motivaram participantes do Ponto de Encontro e Cultura PEC/Projeto Metuia-USP (BARROS et al., 2013, 2016) a buscar maior compreensão da experiência dos/das artistas de rua no centro da cidade de São Paulo. A pesquisa foi realizada por uma equipe composta por estudantes de graduaçáo em terapia ocupacional, além de terapeutas ocupacionais e docentes do Projeto Metuia-USP, um dos músicos que trabalhavam no centro da cidade de Sáo Paulo e duas pessoas ligadas a movimentos sociais de luta por direitos das pessoas em situaçáo de rua e que participavam da fruição artística presente na região central da capital paulista. Realizamos dois encontros iniciais para definir o itinerário a ser percorrido, o uso de equipamentos e, sobretudo, para discutir os objetivos e a metodologia da pesquisa. Houve uma necessidade inicial de compreender a diferenciação entre os chamados artistas de rua e os artistas em situação de rua, pois, segundo a definição de nossos interlocutores do PEC, havia artistas que compreendiam o espaço público como local privilegiado de trabalho para divulgação de sua arte e aqueles que, por uma série de rupturas, chegaram à situação de rua.

A proposta nasceu num momento histórico em que a Prefeitura paulistana passou a coibir a presença dos artistas, inclusive com a apreensão de seus instrumentos musicais. Guiados por João da Viola, poeta e músico que se identifica com a música sertaneja de raiz, realizamos, durante cerca de dez encontros, o mesmo trajeto que representava os seus pontos de referência: Praça da Sé, Rua Quinze de Novembro, Largo Sáo Bento, Praça Ramos, Praça da República e Parque da Luz.

Os exercícios etnográficos permitiram o encontro com pessoas e grupos de artistas dos mais variados estilos e formas de relação com o espaço público. Foi na Rua Quinze de Novembro em que conhecemos Marcos Rasta. Nascido no interior do Ceará, já circulou por várias cidades brasileiras e da América Latina. É exemplo de uma gama de artistas que se apresentam em espaços públicos, de forma itinerante, e compreendem que este fazer artístico tem algo de sagrado. Entende que faz parte de um coletivo de artistas que têm a capacidade de enfrentar os imprevistos de se apresentar na rua e cuja função social é divulgar e tornar mais acessíveis as diversas expressôes artísticas, que, no seu caso, é a música. Esta perspectiva era traduzida pela expressão "o artista vai onde o povo está!", a qual escutamos inúmeras vezes nestes exercícios etnográficos. No entanto, notou-se, desde o início, a importante crítica em relação à criminalização dos artistas de rua. De forma contundente, Marcos Rasta refletiu:

Eu acho que a geração dos 50 anos ainda está segurando bem o manifesto de cultura de rua. Para tocar na rua, a gente procura os caminhos, se você ficar é porque é um artista de rua, se não tiver a coragem que eu e Montreal temos [...]. É uma onda espiritual, eu acho, é místico, é uma força que guia, porque é difícil cantar na rua. [...] Seria bom se em São Paulo o manifesto de cultura de rua crescesse e as pessoas dessem mais valor, em especial as autoridades que precisam aprender a distinguir quem é artista e quem é bandido! [...] Eu já vi cara fardado dando chute no rosto do cara que dormia na rua, isso está certo? E como as pessoas vão saber disso? É por isso também que eu faço música, essa denúncia vai para as minhas letras (GALVANI, 2015, p. 44).

Nosso interlocutor parece sintetizar aspectos importantes da experiência dos e das artistas de rua, cunhada numa identidade coletiva, representada pela coragem, pelas habilidades artísticas do improviso, pela flexibilidade ao lidar com o público, pela invisibilidade diante das políticas culturais e pela exposição aos dilemas e contradiçôes da cidade, vistos de perto, fortemente identificados pela truculência da polícia em relação aos próprios artistas e também com as pessoas em situação de rua.

O manifesto de cultura de rua, assim denominado por Marcos Rasta e por um conjunto de artistas que compreendem a rua, ou seja, o espaço público como espaço privilegiado destes fazeres artísticos será narrado a seguir a partir da identificação de "pedaços", como campos de interação que alimentam laços de solidariedade (MAGNANI, 2003), espaço de trocas econômicas, afetivas e simbólicas, e de construção de atividades significativas (BARROS et al., 2013). A narrativa dá destaque a alguns artistas nesta relação com o espaço público.

\subsection{O sanfoneiro e a Praça da Sé}

A primeira narrativa decorre de exercício etnográfico realizado na Praça da Sé. Feira do rolo, cabeleireiro, pregadores, cartomantes, transeuntes, policiais, banda de forró, artes circenses, pessoas em situação 
de rua, turistas...pausa, encontro, debate, confronto, sons e movimento. A Praça da Sé tornou-se um espaço de experimentaçôes humanas e, igualmente, rica para etnografias que buscam compreender os significados de diferentes fazeres que ali coexistem, nem sempre pacificamente (GALVANI; BARROS, 2010; DINIZ, 2013; FREHSE, 2013). Na Praça da Sé, nos aproximamos de expressão artística que se tornou referência neste espaço, em um determinado momento histórico: o Piauí da Sanfona e a sua Banda Luar do Sertão. Piauí, sanfoneiro, era reconhecido pelos outros artistas de rua e pelo seu público que ali interagia como um artista valioso, pois são raros aqueles que conseguem tocar uma bela sanfona, diziam seus admiradores. Piauí era acompanhado por um tocador de triângulo, outro de zabumba, uma bailarina e um bailarino, além de usar equipamento de som. Foi interessante observar que Piauí era uma referência para outros artistas de rua: de um lado, por conseguir uma infraestrutura para seu trabalho na rua, que se diferenciava de outras experiências, pois ele tinha uma banda, equipamentos de som, além de uma boa relação com os policiais da Praça. Havia algumas classificaçóes entre os artistas de rua: uma delas era representada por aqueles que eram considerados "profissionais" e aqueles entáo considerados "aventureiros". Piauí da sanfona estava entre os profissionais. Além de acumular experiência e ter legitimidade entre seus pares, era reconhecido pela solidariedade em colaborar com quem iniciava a carreira, além da clareza na defesa de uma forma de trabalho e de ocupação da cidade, como expressou:

Esse negócio de não autorizar a trabalhar na rua está errado. A gente tem que partir para cima com garra, brigar mesmo, porque quem construiu isto aqui fomos nós, que viemos do nordeste ajudar a construir esta cidade, a gente tem que desfrutar, tem que lutar para levar o pão para os pequenos em casa, né? (PIAUÍ DA SANFONA, 2009).

Na dinâmica da Praça da Sé, com muita facilidade se forma uma roda em torno de um acontecimento. Percebíamos que nossa presença e nossos equipamentos eram também motivadores de aglutinaçóes e de curiosidade. Uma das análises positivas feitas pela equipe de pesquisa no processo foi perceber que tal curiosidade aflorava em diversos debates em torno da nossa temática de interesse, com destaque para a necessidade de descriminalizar o trabalho do artista de rua e possíveis estratégias.

Este debate retornava aos encontros da equipe de pesquisa, ao coletivo maior situado nos encontros do $\mathrm{PEC}$, além dos espaços de reflexão na universidade, como o retorno às supervisóes de estágio e disciplinas teóricas em terapia ocupacional social. Uma das articulaçôes possíveis foi a ampliação do repertório dos movimentos de defesa de direitos da populaçáo em situação de rua, para incorporar as demandas dos artistas de rua nas suas pautas. Houve também a mobilização para a construção de um texto, em forma de manifesto, em favor da descriminalização dos artistas de rua e da necessidade de políticas de valorização do seu trabalho. O texto foi distribuído pelos artistas no centro da cidade e circulou por outros espaços de debate político. A articulação entre arte e política se evidencia, aqui, como parte do esforço de coabitar o espaço público e de se engajar no debate sobre o lugar comum. O potencial inovador da atividade está na conjugaçấo atividade-ação, para a garantia do direito à cidade. A terapia ocupacional, ao assumir essa dimensão política na disputa pelo espaço público, intensifica seu trabalho com movimentos sociais. Além disso, ganha competência e se assume como campo de saber que escapa ao seu necessário atrelamento às relaçóes trabalho-emprego ou às políticas sociais no âmbito do Estado. A profissionalidade se constitui pela interlocução com grupos sociais, na construçáo de projetos comuns e de saberes partilhados sobre a cidade.

\subsection{Piano da estação da $\mathrm{Luz}^{2}$ : acesso aberto}

Esta narrativa se desenvolveu em torno do exercício etnográfico realizado na Estação do Metrô da Luz, mais precisamente na dinâmica promovida pelo piano instalado em seu corredor de passagem. Carlinhos Luz, músico, compositor e frequentador assíduo do Sarau do Ponto de Encontro e Cultura (PEC - Metuia-USP), fazia uso frequente do piano. Chamou-nos atenção a dinâmica provocada por Carlinhos na Estação do Metrô da Luz: ao se apropriar do piano disponível no saguão, entoava cançôes animadas, que proferiam mensagens de paz. O músico iniciava sua performance e logo formava-se uma roda em torno dele. O movimento da Estação era curioso. Alguns passavam rapidamente, outros paravam na roda para observar por algum tempo; havia aqueles que se dirigiam ao local para ouvir e serem ouvidos. Intercalava cançóes da banda Legião Urbana e suas próprias composiçóes. As pessoas faziam pedidos, e, não raro, Carlinhos realizava alguma venda de $\mathrm{CD}$, de forma discreta, para não chamar a atençáo dos funcionários da Companhia do Metrô. $\mathrm{O}$ músico dedicava atenção especial às trabalhadoras do sexo, pois se preocupava com este 
cotidiano adverso que observava e com o preconceito que sofriam. Como uma espécie de releitura do São Gonçalo $^{3}$, Carlinhos privilegiava este local, pois tentava atrair a atençáo das trabalhadoras do sexo. Com suas mensagens de amor a Deus, acreditava que poderia sensibilizá-las a buscar alternativas de vida.

Alguns irmãos de fé reconheciam em suas cançóes mensagens bíblicas ligadas a sistemas religiosos neopentecostais e, nos intervalos, o procuravam para falar de suas Igrejas e compartilhar aspectos de sua fé: eles se desdobravam em reflexôes sobre a Bíblia e a atualidade. Na roda que cercava o piano, ouviam-se comentários sobre seu talento e o quanto merecia maior reconhecimento. $\mathrm{O}$ instrumento musical alterava radicalmente o ritmo e o cenário do saguão daquela estação de metrô, e Carlinhos fazia parte desta composição. Para alguns, apenas passagem; para outros, diversão, trabalho, encontro e possibilidades de troca.

O piano da Estação da Luz era também o pedaço da Cydoka. Durante três anos, ela o frequentou quase diariamente. Privilegiava-se daquela dinâmica, da qual também fazia parte, para divulgar seu DVD, produzido artesanalmente. A artista compreendia que a música é uma missão designada por Deus e percebia que, ao realizar tal missão, conseguia atrair para si acontecimentos positivos, em constante relação com o que denominou de entidades (espíritos) boas e ruins, as quais faziam interferência em seu cotidiano e em suas projeçóes para o futuro. Em suas palavras:

[...] quando eu venho tocar, principalmente quando tem público assim, aquelas pessoas são alegres, elas falam pra mim que saem de alma lavada. Então eu acredito na espiritualidade, aquela energia positiva, eu capto. Graças a Deus (GALVANI, 2015, p. 100).

Usuária de um albergue da cidade, Cydoka tinha como expectativa voltar a morar em uma casa, com suas regras e com seus modos de vida. Com fé, música e muita paciência, ela administrava as redes invisíveis e concretas, e seguia ampliando seus contatos e usufruindo da melhor forma possível da dinâmica que os pianos que se encontram no espaço público propiciavam, respondendo ao chamado “Toque-me, Sou Teu!".

Ressaltamos, neste relato, a problemática do viver junto em espaços públicos. A imensa desigualdade presente na sociedade brasileira torna a partilha do bem público um território intensamente conflituoso. Em espaços assim constituídos, as atividades em terapia ocupacional precisam adotar uma configuração de mediação dialógica da partilha e da coabitação da diferença.

\subsection{Arte da viola e violeiros do Parque da Luz}

Foi no Parque da Luz que o exercício etnográfico ganhou maior densidade, por ser este o pedaço dos violeiros e, portanto, de João da Viola, membro de nosso grupo. No Parque da Luz, diversos violeiros podem ser vistos, ora conversando, ora entoando suas violas; eles fazem clara distinção entre a música sertaneja de raiz e a música sertaneja "moderna", debate fundamental para definir "nós" e os "outros". A viola, o violáo e as duas vozes atestam a qualidade das duplas de artistas, que não precisam de mais nenhum instrumento para se apresentar; no máximo, um sanfoneiro. São violeiros experientes, geralmente nascidos em cidades do interior paulista, cuja formação musical deu-se, inicialmente, em rituais religiosos e de trabalho das comunidades rurais. Compartilham certa reverência a artistas como Tonico e Tinoco, Pena Branca e Xavantinho, entre outros, e desaprovam o papel histórico desempenhado por determinados artistas, como Chitãozinho e Xororó, Leandro e Leonardo, entre outros, que "deformaram a música sertaneja de raiz", dizem os violeiros, ao incorporarem outros instrumentos musicais, como bateria e guitarra. Como lembrou Waldenir Caldas (1999), haveria uma diferença da função social de uma vertente e de outra: enquanto a música de raiz teria, como uma de suas principais funçóes, facilitar as relaçóes sociais entre a comunidade, a música sertaneja, por sua vez, estaria associada a um produto que objetiva o lucro, sofrendo transformaçóes nos seus componentes formais, nos instrumentos utilizados, na temática e no tempo de duração. Ainda que os aspectos rituais religiosos estejam ausentes na dinâmica que observamos no Parque da Luz, a viola e a música sertaneja de raiz exercem uma função agregadora de pessoas de diferentes cantos da cidade, classes sociais e expectativas em relação à música.

Diferentemente da Praça da Sé, da Rua XV de Novembro e da Estação da Luz, o Parque da Luz era local de pausa, silêncio, contemplação. Local privilegiado de encontros de nosso guia João da Viola. Esta interação com os violeiros desdobrou-se em duas propostas no Parque da Luz: a produção de um DVD com os violeiros e a realização de um sarau no Parque, açóes estas que se articularam, posteriormente, com o PEC. As açôes eram lidas como estratégias de ocupar o espaço, valorizar a produçáo artística e tentar uma aproximação pacífica e diplomática com os seguranças do Parque, que também foram convidados a participar das iniciativas. $\mathrm{O}$ debate sobre o direito à cidade se renova constantemente 
e as regulaçóes sobre o espaço urbano interferem nos cotidianos de quem tem, no espaço público, sua referência. A cultura, compreendida como direito e como teia de significados tecidos em relaçóes desiguais, é norteadora das atividades erguidas como saber partilhado e imerso em relações dialógicas e econômicas.

\section{Dialogia como Ética da Relação}

No campo das formulaçôes teóricas de Paulo Freire, a dialogia constitui conceito ético-metodológico chave. Nós o assumimos, somado a outras reflexóes acerca da relação pesquisador-pesquisado, como as de Roberto Cardoso de Oliveira (2000), para quem o trabalho etnográfico envolve a procura da cooperação, e, portanto, da recusa metodológica assentada na assimetria. Esse esforço de estabelecimento de relaçôes horizontais - e, portanto, dialógicas - é base para o conhecimento. Apoiadas nesta abordagem é que formulamos os exercícios etnográficos, a fim de entrelaçar perspectivas - de pessoas diversas, social e culturalmente - distintas na construçáo do conhecimento e, igualmente, nas práticas de ensino e práticas de pesquisa. Maria Luisa Sandoval Schmidt (2006) sugere a revisão ética e política na pesquisa, para a construçáo de uma perspectiva da interlocução no encontro etnográfico, considerado como diálogo, negociação e interlocução culturais:

Nestas atitudes vislumbra-se uma abertura para considerar o outro como parceiro na construção de interpretações da cultura e para empreender a reflexão sobre as relaçóes de poder entre pesquisador e pesquisado, bem como sobre o sentido ou a utilidade da pesquisa etnográfica para um e outro (SCHMIDT, 2006, p. 27).

Deparamo-nos, constantemente, com a necessidade de desenvolver interpretaçóes sobre grupos sociais, comunidades ou trajetórias pessoais. Contudo, tais grupos e pessoas produzem igualmente interpretaçóes sobre diferentes ângulos. Há, portanto, uma pluralidade de interpretaçóes que precisam ser analisadas tanto durante o trabalho de campo como no processo de análise em pesquisa. Compreende-se que tal pluralidade de perspectivas também precisa ser analisada durante a construção de açôes e tecnologias sociais em terapia ocupacional social, alimentando as reflexóes em torno da construçáo de metodologias de ação em situaçóes de trabalho territorial e comunitário, em situaçóes de desigualdade social, diversidade cultural, pluriétnica e multirracial (BARROS; GALVANI, 2016).

É neste sentido que as ponderações de Amadou Hampâté Bâ (2010, p. 211) favorecem a desconstrução da hierarquia na produção de conhecimento, à medida que desvela conflito e disputa na relação com o Outro. Para o intelectual malinês, um jovem pesquisador deveria ter como características:

[...] O "coração de uma pomba" para nunca se zangar nem se inflamar, mesmo se lhe disserem coisas desagradáveis. Se alguém se recusa a responder sua pergunta, inútil insistir; vale mais instalar-se em outro ramo. Uma disputa aqui terá repercussóes em outra parte, enquanto uma saída discreta fará com que seja lembrado e, muitas vezes, chamado de volta. "A pele de um crocodilo", para conseguir se deitar em qualquer lugar, sobre qualquer coisa, sem fazer cerimônias. Por último, "o estômago de uma avestruz", para conseguir comer de tudo sem adoecer ou enjoar-se. A condição mais importante de todas, porém, é saber renunciar ao hábito de julgar tudo segundo critérios pessoais. Para descobrir um novo mundo, é preciso saber esquecer seu próprio mundo, do contrário o pesquisador estará simplesmente transportando seu mundo consigo ao invés de manter-se "à escuta".

No contexto da discussão da tradição oral africana, a metáfora orienta-nos no sentido do difícil exercício da complexidade, a fim de interagir com plasticidade e criatividade sem, contudo, esquecer a pergunta mobilizadora.

Os exercícios etnográficos, pautados como ética da ação-relação, passam a ser considerados processos de participaçáo social e política, nos quais

[...] é fundamental considerar um equilíbrio mutuamente possível, de autonomia, cooperação e hierarquia com e entre as pessoas, sendo a tomada de decisão partilhada entre todos os parceiros do processo de investigação (SOARES; SARMENTO; TOMÁS, 2005, p. 56).

O circuito dos artistas no centro da cidade de São Paulo delimitou cenários, interlocutores, regras e script, favorecendo a busca de estratégias para distanciar o olhar do senso comum (MAGNANI, 1996). Neste contexto, são oportunas as contribuiçóes da antropologia urbana, particularmente por meio dos conceitos elaborados por Magnani (1996, 2002, 2003), pois, há vários anos, estes têm alimentado nossas reflexôes no âmbito de atividades de ensino, pesquisa e extensão, em terapia ocupacional 
social (GALVANI; BARROS, 2010; BARROS; GALVANI, 2016). As noçôes de pedaço, trajetos (fluxos pela cidade) e circuitos (rede de espaços, pedaços e equipamentos referentes a determinadas práticas ou oferta de serviços) serviriam de alicerce para a leitura das dinâmicas da cidade associadas a grupos sociais específicos: adultos em situação de rua, pessoas em permanente interação com a rua, artistas de rua e imigrantes.

\section{Exercícios Etnográficos e Urbanidade: Atividades como (Inter)ação em Setting Social em Disputa}

Não há como negar, assim como alerta Magnani (2003), que, ao pensar as metrópoles a partir de um ponto de vista macro, são proeminentes os processos desagregadores, tais como o colapso do sistema de transporte, as deficiências do saneamento básico, o déficit de moradia, a má distribuição dos equipamentos sociais, além da poluição, da violência e do sentimento de solidão, entre outros. São dimensôes reveladas na perspectiva demográfica, mas que são experimentados, também, cotidianamente. Porém, interessam-nos principalmente as dimensóes micro das dinâmicas da cidade, já que nelas encontram-se importantes formas de dialetização e de criaçôes de alternativas a processos desagregadores.

A cidade de São Paulo passou por aceleradas transformaçóes nos últimos cem anos. De acordo com Claude Lévi-Strauss (1996), a transformação seria a base da essência das grandes cidades americanas. Disse o antropólogo:

Nas cidades do Novo Mundo, seja Nova York, Chicago ou São Paulo, que muitas vezes lhe foi comparada, o que me impressiona não é a falta de vestígios: essa ausência é um elemento de seu significado. [...] Para as cidades europeias, a passagem dos séculos constitui uma promoção; para as americanas, a dos anos é uma decadência. Pois não são apenas construídas para se renovarem com a mesma rapidez com que foram erguidas, quer dizer, mal. No momento em que surgem, os novos bairros nem sequer são elementos urbanos: são brilhantes demais, novos demais, alegres demais para tanto (LÉVI-STRAUSS, 1996, p. 69).

Neste processo, uma das transformaçóes significativas que modificaram o cotidiano na cidade de São Paulo, nas últimas décadas, está relacionada ao debate sobre as concepçóes de rua e às disputas pelo espaço público. Os processos de urbanização das grandes cidades brasileiras, como refere Magnani (1996), sofreram forte influência da reformulação de algumas cidades europeias, a exemplo de Paris do século XIX e seus grandes bulevares. Com as transformaçóes urbanas e o avanço do capitalismo, outras mudanças foram consideradas necessárias, o que Magnani, ao citar Le Corbusier ${ }^{4}$, define como urbanismo de racionalidade. Para Le Corbusier, era necessário "matar a rua", ou seja, ordenar, delimitar o espaço da casa, do trabalho, do lazer.

João do Rio $(2009$, p. 8) lembra a centralidade da rua e seus significados, muitas vezes confusos e antagônicos, para o homem urbano:

Se a rua é para o homem urbano o que a estrada foi para o homem social, é claro que a preocupação maior, a associada a todas as outras ideias do ser das cidades, é a rua. Nós pensamos sempre na rua. Desde os mais tenros anos ela resume para o homem todos os ideais, os mais confusos, os mais antagônicos, os mais estranhos, desde a noção de liberdade e de difamação - ideias gerais — até a aspiraçáo de dinheiro, de alegria e de amor, ideias particulares. Instintivamente, quando a criança começa a engatinhar, só tem um desejo: ir para a rua! Ainda não fala e já a assustam: se você for para a rua encontra o bicho! Se você sair apanha palmadas!

No âmbito das ciências sociais brasileiras, Fraya Frehse ressalta que a rua passou a ser concebida como categoria sociológica a partir da década de 1970, sob a influência das elaboraçóes da obra "A casa e a rua", de Roberto da Matta (1985), para quem a rua "sintetiza o aspecto público, não controlado do mundo urbano” (MATTA apud FREHSE, 2013, p. 102). Deste modo, a rua assume diversos significados nas pesquisas em ciências sociais no Brasil, que têm como referência os grandes centros urbanos, os quais Frehse busca explicitar no seguinte agrupamento: há um conjunto de pesquisas que trazem, para o primeiro plano, "a rua como espaço de desigualdade social"; "a rua como espaço de criatividade, nas relaçóes de protagonistas definidos entre si e com terceiros"; "associação entre a rua, padrôes da vida privada e da vida pública" e, por fim, "abordagens da sociabilidade conflituosa na rua", como as tensóes com o poder público e as políticas de gentrificação (FREHSE, 2013, p. 101).

A pluralidade de significados que a rua adquire, seja no âmbito das ciências sociais ou na perspectiva do cronista e poeta, convida a pensar de que rua se pretende tomar como objeto de reflexáo. Neste 
sentido, recorremos novamente ao Magnani (1996, p. 3) para compartilhar o interesse pela rua que

[...] identificada pelo olhar antropológico é recortada desde outros e variados pontos de vista, oferecidos pela multiplicidade de seus usuários, suas tarefas, suas referências culturais, seus horários de uso e formas de ocupação.

Buscamos, assim, a experiência da rua, exatamente esta que se quis "matar", retomando a expressão de Le Corbusier. Com o processo de urbanização, novos circuitos são possíveis de serem criados e novas figuras aparecem no cenário urbano, a exemplo da multidáo e do flâneur evocados por Benjamin (1989), ao expor suas preocupaçóes com os processos de urbanização e modernização europeus, sobretudo em Paris. A exemplo dos boêmios e poetas de Baudelaire, há notícias da cidade que só alguns podem dar. São essas notícias da cidade que são valorizadas nesta reflexão, fundamentais na construção de atividades significativas em terapia ocupacional social (BARROS et al., 2013).

A noção de "pedaço" proposta por Magnani é, desta forma, particularmente interessante, pois, em diálogo com a dicotomia 'rua em oposição a casa' (MATTA, 1985), evidencia-se outro plano, o dos "chegados". Se a casa é o domínio dos parentes e a rua, o dos estranhos, a noção de pedaço permite desvelar

[...] um campo de interação em que as pessoas se encontram, criam novos laços, tratam das diferenças, alimentam, em suma, redes de sociabilidade numa paisagem aparentemente desprovida de sentido ou lida apenas na chave da pobreza ou exclusão (MAGNANI, 2003, p. 86).

Esta experiência renova a necessidade de reflexáo sobre o constante exercício de crítica de posiçôes cristalizadas sobre a dimensão coletiva do conhecimento. Afinal, quem ensina quem? Ela nos remete, ainda, à criação de tecnologias no campo da terapia ocupacional social. Ler o contexto e criar campos partilhados de criação (estudantes, terapeutas, pesquisadores, comunidade, grupos sociais) são movimentos necessários para a emersão conjunta da (na) cotidianidade e para a transformaçáo social (BARROS, 2004; FREIRE, 2011).

A terapia ocupacional social aqui, em proposta, realiza-se nesta dinamicidade e plasticidade própria da experiência da diferença, com processos intensos de negociação, envolvendo múltiplas racionalidades e diferentes formas de apreensão do real que, ao dialogarem, gestam possibilidades de ação de sentidos múltiplos e adensam o próprio conceito de atividades no bojo do contexto social e cultural. Este é, também, o sentido dos exercícios etnográficos enquanto ação-interaçáo, que confere e materializa a própria noção de atividades em sua dimensão antropológica e política, situada e contextualizada na ética da dialogia.

A vida itinerante e as características dos espaços de sociabilidade significativos e reconhecidos pelos/as colaboradores/as dos exercícios etnográficos criaram, para os terapeutas ocupacionais e estudantes envolvidos, uma forte exigência de inovaçáo de tecnologia para pensar e desenvolver (inter)ação em setting social, territorial e socialmente definido. Neste caso, trata-se de segmentos da população que vivenciam regularmente diferentes formas de desqualificação (PAUGAM, 1999) - social, cultural ou intelectual (GALVANI, 2008) - e/ou processos de ruptura de redes de suporte sociais ou afetivas (CASTEL, 1994; BARROS, 2004; BARROS et al., 2002, 2007).

Concluímos, assim, que os exercícios etnográficos realizados formam um instrumental de abordagem na terapia ocupacional social que deve ser mais bem compreendido e desenvolvido. Os objetivos iniciais de geração de processo de ensino de graduação alicerçado em práticas de pesquisa mostraram-se promissores e profícuos. Percebeu-se que, por meio da transformaçáo de posiçôes entre educador-educando, pesquisador-interlocutor, pesquisa-sala de aula e entre setting privado de ação do terapeuta ocupacional e setting público, foi possível definir os contornos de açôes devido à noçáo abrangente e aberta do conceito de atividades. Estas conduziram à exigência ética do sentido, pois náo conformavam ao campo da estética da manualidade, nem à reduçáo ao trabalho como mercado e satisfação de necessidades básicas ou da participação social como lógica assistencial.

Os exercícios etnográficos definem-se, finalmente, como atividade-conhecimento de saberes plurais e, por vezes, contraditórios. As atividades dos artistas são, para concluir, expressóes éticas e estéticas de modalidades do fazer humano, assim como da construção do cotidiano referenciado no espaço público. As atividades dos artistas são, igualmente, formas de lhes conferir sentido e de disputar a palavra pública.

Deste modo, o trabalho do terapeuta ocupacional, engajado em movimentos sociais e culturais, ancora-se em projetos de emancipação e de pluralização do espaço público entendido como bem comum. Neste, insere-se a emergência de palavras singulares e de narrativas coletivas em um campo de lutas sociais. A cultura efetiva-se como arma para a conquista 
da partilha do direito à palavra e à construção do conhecimento.

É, portanto, no fazer da arte e da política que a terapia ocupacional inscreve sua ação mediadora e criativa, e reedifica a noçấo mesma de atividade e o lugar de um campo de saber que vai além de um espaço profissional, nas disputas corporativas. O ensino de terapia ocupacional tem, portanto, significados, tessituras teóricas e experimentaçóes criativas que precisam escapar do aprisionamento excessivo à profissionalizaçáo. A terapia ocupacional social engaja-se, desta forma, na contribuição do entendimento das transformaçóes culturais e políticas do fazer humano, imerso nas intersecções entre práticas artísticas e narrativas emergentes dos ativismos urbanos insurgentes das últimas décadas.

\section{Agradecimentos}

Estas reflexôes não seriam possíveis sem a colaboração de João Rodrigues da Rocha, Jovenil Ribeiro e todos e todas os/as artistas que compartilharam suas experiências conosco.

\section{Referências}

BARROS, D. D. Terapia ocupacional social: o caminho se faz ao caminhar. Revista de Terapia Ocupacional da Universidade de São Paulo, São Paulo, v. 15, n. 3, p. 90-97, 2004.

BARROS, D. D. et al. Terapia Ocupacional Social. Revista de Terapia Ocupacional da Universidade de São Paulo, Săo Paulo, v. 13, n. 3, p. 95-103, 2002.

BARROS, D. D. et al. Terapia ocupacional social: diversidade, cultura e saber técnico. Revista de Terapia Ocupacional da Universidade de São Paulo, Sáo Paulo, v. 18, n. 3, p. 128-134, 2007.

BARROS, D. D. et al. Cultura, economia, política e saber como espaços de significação na terapia ocupacional social: reflexões sobre a experiência do Ponto de Encontro e Cultura. Cadernos de Terapia Ocupacional da UFSCar, São Carlos, v. 21, n. 3, p. 583-594, 2013.

BARROS, D. D. et al. Cultura, economia, política e saber como espaços de significaçáo na terapia ocupacional social: reflexóes sobre a experiência do Ponto de Encontro e Cultura no Metuia em São Paulo. In: ALGADO, S. S. et al. Ocupacionales desde el Sur: derechos humanos, ciudadanía y participación. Chile: Editorial Universidad USACH, 2016. p. 303-320.

BARROS, D. D.; GALVANI, D. Terapia Ocupacional: social, cultural? Diversa e múltipla! In: LOPES, R. E.; MALFITANO, A. P. S. (Org.). Terapia Ocupacional Social: desenhos teóricos e contornos práticos. São Carlos: EdUFSCar, 2016. p. 83-116.
BARTHES, R. Roland Barthes por Roland Barthes. São Paulo: Estação Liberdade, 2003.

BENJAMIN, W. Sobre alguns temas em Baudelaire. In: BAUDELAIRE, C. Um lírico no auge do capitalismo. São Paulo: Brasiliense, 1989. p. 149-203.

CALDAS, W. O que é música sertaneja. São Paulo: Brasiliense, 1999.

CASTEL, R. Da indigência à exclusão, a desfiliação: precariedade do trabalho e vulnerabilidade relacional. In: LANCETTI, A. (Org.). Grupos e coletivos. São Paulo: Hucitec, 1994. p. 21-48.

DINIZ, B. F. Os indesejáveis da Praça da Sé (SP): uma aproximaçáo etnográfica. Ponto Urbe, São Paulo, n. 12, p. 1-17, 2013.

FREHSE, F. A rua no Brasil em questão (etnográfica). Anuário Antropológico, São Paulo, n. 2012-II, p. 99-129, 2013.

FREIRE, P. Pedagogia do oprimido. Rio de Janeiro: Paz e Terra, 2011.

GALVANI, D. Pessoas em situação de rua na cidade de São Paulo: itinerários e estratégias na construção de redes sociais e identidades. 2008. 261 f. Dissertação (Mestrado em Ciências da Reabilitação) - Universidade de São Paulo, São Paulo, 2008.

GALVANI, D. Circuitos e práticas religiosas nas trajetórias de vida de adultos em situação de rua na cidade de São Paulo. 2015. 197 f. Tese (Doutorado em Psicologia) Universidade de São Paulo, São Paulo, 2015.

GALVANI, D.; BARROS, D. D. Pedro e seus circuitos na cidade de São Paulo: religiosidade e situaçáo de rua. Interface: Comunicaşão, Saúde, Educação, Botucatu, v. 14, n. 35, p. 767-779, 2010.

HAMPATÉ BÂ, H. A tradição viva. In: KI-ZERBO, J. História geral da África I: metodologia e pré-história da África. Brasília: UNESCO, 2010. p. 167-212.

LÉVI-STRAUSS, C. O novo mundo. In: LÉVI-STRAUSS, C. Tristes trópicos. São Paulo: Companhia das Letras, 1996. p. 69-91.

MAGNANI, J. G. C. Rua, simbolo e suporte da experiência urbana. São Paulo: Laboratório do Núcleo de Antropologia Urbana da USP, 1996. Disponível em: <http:// nau.fflch.usp.br/sites/nau.fflch.usp.br/files/upload/paginas/rua_simbolo\%20e\%20suporte $\% 20 \mathrm{da} \% 20$ experiencia\%20-\%20magnani.pdf>. Acesso em: 10 set. 2016.

MAGNANI, J. G. C. De perto e de dentro: notas para uma etnografia urbana. Revista Brasileira de Ciências Sociais, São Paulo, v. 17, n. 49, p. 11-29, 2002.

MAGNANI, J. G. C. A antropologia urbana e os desafios da metrópole. Tempo Social, São Paulo, v. 15, n. 1, p. $81-95,2003$.

MATTA, R. A casa e a rua. São Paulo: Brasiliense, 1985. 
OLIVEIRA, R. C. O trabalho do antropólogo: olhar, ouvir, escrever. In: OLIVEIRA, R. C. O trabalho do antropólogo. São Paulo: Edunesp, 2000. p. 17-35.

PAUGAM, S. O debate em torno de um conceito. In: VERÁS, M. P. B. Por uma sociologia da exclusão social: o debate com Serge Paugam. São Paulo: Educ, 1999. p. 115-142.

PIAUÍ DA SANFONA. Entrevista. Acervo Projeto Metuia/USP. [s.l.]: [s.n.], 2009.

RIO, J. A alma encantadora das ruas. Rio de Janeiro: Fundação Biblioteca Nacional, 2009. Disponível em: <http:// www.dominiopublico.gov.br/download/texto/bn000039. pdf>. Acesso em: 15 jan. 2015.

SCHMIDT, M. L. S. Pesquisa participante: alteridade e comunidades interpretativas. Psicologia USP, São Paulo, v. 17, n. 2, p. 11-41, 2006.

SOARES, N. F.; SARMENTO, M. J.; TOMÁS, C. Investigação da infância e crianças como investigadoras: metodologias participativas dos mundos sociais das crianças. Nuances: Estudos sobre Educação, Presidente Prudente, ano XI, v. 12, n. 13, p. 49-64, 2005.

\section{Contribuição dos Autores}

As autoras trabalharam nas diferentes etapas de elaboração do texto. Todos os autores aprovaram a versão final do texto.

\section{Fonte de Financiamento}

FAPESP (Processo 2012/02958-4) e da Pró-reitoria de Cultura e Extensão Universitária da USP (PRCEU/ USP).

\section{Notas}

${ }^{1}$ Núcleo USP do Projeto Metuia - Grupo interinstitucional de estudos, formação e açóes pela cidadania de crianças, adolescentes e adultos em processos de ruptura das redes sociais de suporte, criado em 1999, no âmbito da USP, UFSCar e PUC-Campinas.

${ }^{2}$ Projeto Toque-me, Sou Teu!, do artista inglês Luke Jerram, em parceria com o Sesc-SP, iniciado em outubro de 2008.

${ }^{3}$ São Gonçalo é conhecido como santo protetor dos violeiros. Uma de suas práticas era dançar com as mulheres, trabalhadoras do sexo, até cansarem, de modo a se desligarem das atividades de seu trabalho.

${ }^{4}$ Arquiteto e urbanista franco-suíço, responsável por redigir a Carta de Atenas, manifesto urbanístico resultante do IV Congresso Internacional de Arquitetura Moderna (CIAM), realizado em Atenas em 1933. 